\title{
Phenol-Hyaluronic Acid Conjugates: Correlation of Oxidative Crosslinking Pathway and Adhesiveness
}

\author{
Jungwoo Kim ${ }^{1,2}$, Sumin Kim ${ }^{1,2} \mathbb{D}$, Donghee Son ${ }^{3,4,5, * \mathbb{D}}$ and Mikyung Shin $1,2,5, * \mathbb{D}$ \\ 1 Department of Biomedical Engineering, Sungkyunkwan University (SKKU), Suwon 16419, Korea; \\ wjddn1998@naver.com (J.K.); ally0618@naver.com (S.K.) \\ 2 Department of Intelligent Precision Healthcare Convergence, Sungkyunkwan University (SKKU), \\ Suwon 16419, Korea \\ 3 Department of Electrical and Computer Engineering, Sungkyunkwan University (SKKU), \\ Suwon 16419, Korea \\ 4 Department of Superintelligence Engineering, Sungkyunkwan University (SKKU), Suwon 16419, Korea \\ 5 Center for Neuroscience Imaging Research, Institute for Basic Science (IBS), Suwon 16419, Korea \\ * Correspondence: daniel3600@g.skku.edu (D.S.); mikyungshin@g.skku.edu (M.S.)
}

check for updates

Citation: Kim, J.; Kim, S.; Son, D.; Shin, M. Phenol-Hyaluronic Acid Conjugates: Correlation of Oxidative Crosslinking Pathway and Adhesiveness. Polymers 2021, 13, 3130 . https://doi.org/10.3390/ polym 13183130

Academic Editor: Arn Mignon

Received: 16 August 2021

Accepted: 14 September 2021

Published: 16 September 2021

Publisher's Note: MDPI stays neutral with regard to jurisdictional claims in published maps and institutional affiliations.

Copyright: (c) 2021 by the authors Licensee MDPI, Basel, Switzerland. This article is an open access article distributed under the terms and conditions of the Creative Commons Attribution (CC BY) license (https:// creativecommons.org/licenses/by/ $4.0 /)$

\begin{abstract}
Hyaluronic acid (HA) is a natural polysaccharide with great biocompatibility for a variety of biomedical applications, such as tissue scaffolds, dermal fillers, and drug-delivery carriers. Despite the medical impact of HA, its poor adhesiveness and short-term in vivo stability limit its therapeutic efficacy. To overcome these shortcomings, a versatile modification strategy for the HA backbone has been developed. This strategy involves tethering phenol moieties on HA to provide both robust adhesiveness and intermolecular cohesion and can be used for oxidative crosslinking of the polymeric chain. However, a lack of knowledge still exists regarding the interchangeable phenolic adhesion and cohesion depending on the type of oxidizing agent used. Here, we reveal the correlation between phenolic adhesion and cohesion upon gelation of two different HA-phenol conjugates, HA-tyramine and HA-catechol, depending on the oxidant. For covalent/non-covalent crosslinking of HA, oxidizing agents, horseradish peroxidase/hydrogen peroxide, chemical oxidants (e.g., base, sodium periodate), and metal ions, were utilized. As a result, HA-catechol showed stronger adhesion properties, whereas HA-tyramine showed higher cohesion properties. In addition, covalent bonds allowed better adhesion compared to that of non-covalent bonds. Our findings are promising for designing adhesive and mechanically robust biomaterials based on phenol chemistry.
\end{abstract}

Keywords: hyaluronic acid; phenol; adhesive hydrogels

\section{Introduction}

Hyaluronic acid (HA) is a natural polysaccharide constructed from two alternating units of N-acetyl-D-glucosamine and D-glucuronic acid [1,2]. It is an important component of the extracellular matrix and plays a role in wound healing and in controlling the release of growth factors [3-5]. Previous research has further shown that HA is very versatile in its use in medical treatment and tissue engineering because of its high biocompatibility, biodegradability, viscoelasticity, and non-toxic characteristics [5,6]. These properties make HA an ideal biomaterial for injectable hydrogels, wound patches, 3D bioprinting, tissue scaffolds, and drug delivery [7-11].

However, HA is currently limited in its use, owing to its relatively weak mechanical properties that prevent HA gelation into a hydrogel [8,12-14]. Furthermore, HA is repeatedly enzymatically degraded in a physiological environment because it is vulnerable to hyaluronidase in vivo $[13,15]$. This is an essential hurdle that must be overcome to further utilize HA in tissues, such as photo-crosslinking, Schiff base crosslinking, and click chemistry crosslinking, to extend the duration in vivo and obtain better mechanical properties [16-18]. However, the functionalized molecule has no chemical moieties with 
adhesive properties. These methods do not have the adhesive property needed for certain medical applications such as implant materials for surgical recovery [11,19]. Adhesive properties enable the research to be conducted in the past few years to develop an adhesive HA-derived hydrogel for medical treatment [20].

To achieve good adhesion and mechanical properties simultaneously, polyphenol modification has been introduced. When polyphenol is conjugated with HA, the adhesive strength increases, and polyphenol can be crosslinked. Representative materials of polyphenols with these properties include catechol, tyramine, and gallol, and they can adhere to various substrates through several interactions such as $\pi-\pi$ stacking, hydrogen bonding, electrostatic interaction, and catechol metal correlation [21,22]. In addition, these can be oxidized under basic condition (e.g., $\mathrm{NaOH}$ ) and treatment of $\mathrm{NaIO}_{4}$ or horseradish peroxidase (HRP) to crosslink via covalent bonds, or form coordination complex with metal ions [23]. However, the problem is that the catechol moieties are simultaneously involved in both crosslinking HA backbones and showing their adhesive properties. Crosslinking of phenol molecules causes change of chemical structure of phenol, so it has a possibility of losing adhesion. However, comparative analysis of cohesion and adhesion ability, according to pathway or degree of polyphenol conjugates (HA-Ca and HA-Ty), then made hydrogels using several oxidants (Figure 1). To investigate different crosslinking pathway, biological oxidant (horse radish peroxidase/hydrogen peroxide), chemical oxidant $\left(\mathrm{NaIO}_{4}\right.$, Ammonium persulfate (APS), $\mathrm{NaOH})$, and metal ions $\left(\mathrm{FeCl}_{3}\right)$ were used. Depending on the oxidative pathway of phenol or catechol for gelation, the cohesive and adhesive strength of the HA hydrogels can be balanced because the physical amount and chemical status of these moieties involved in the crosslinking of the polymeric chains would be different. Therefore, in this study, we focused on the comparison of the cohesive and adhesive properties of crosslinked hydrogels.

(a)

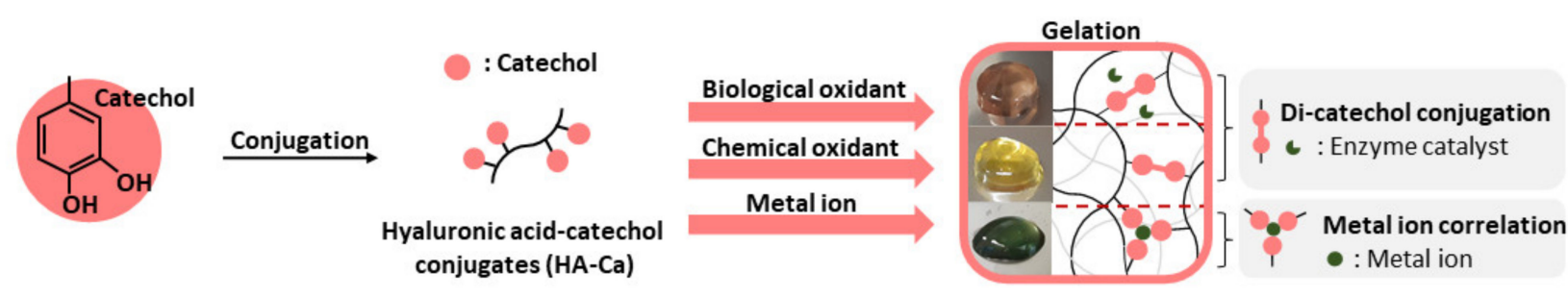

(b)

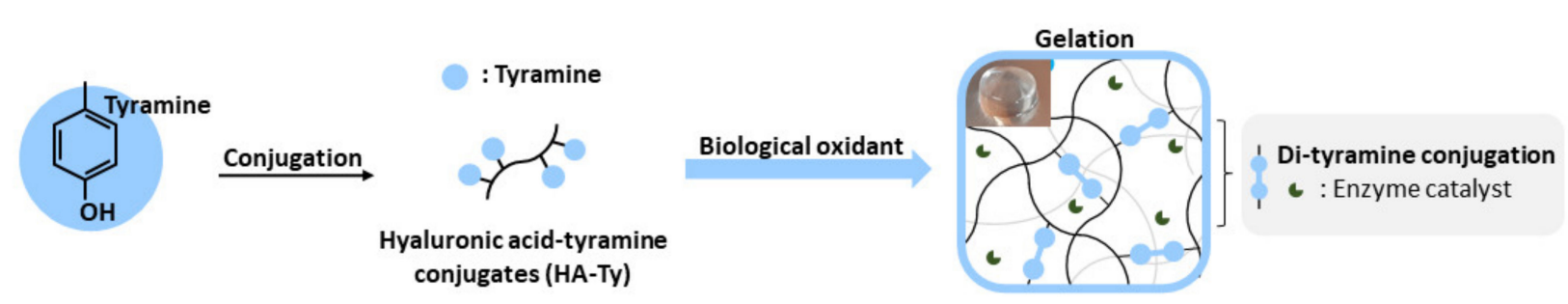

Figure 1. Schematic description of hyaluronic acid-polyphenol hydrogels. (a) Synthesis of HA-Ca conjugates (left) and their gelation by three types of oxidants (right). Biological oxidant and chemical oxidant induce crosslinking of catechol via di-catechol conjugation, and metal ion can be coordinated with catechol. (b) Synthesis of HA-Ty conjugates (left) and the gelation crosslinked by generating di-tyramine under a biological oxidant (right).

\section{Materials and Methods}

\subsection{Materials}

Sodium hyaluronate (Molecular weight $=200 \mathrm{kDa}$ ) was purchased from Lifecore Biomedical (Chaska, MN, USA). Dopamine hydrochloride with catechol and amine groups, tyramine hydrochloride with phenol and amine groups, N-hydroxysuccinimide (NHS), 2(N-morpholino) ethanesulfonic acid (MES) solution (1 M), hydrochloric acid ( $\mathrm{HCl})$, sodium hydroxide $(\mathrm{NaOH})$, horseradish peroxidase $(\mathrm{HRP})$, hydrogen peroxide solution $\left(\mathrm{H}_{2} \mathrm{O}_{2}\right)$, sodium periodate $\left(\mathrm{NaIO}_{4}\right)$, ammonium persulfate (APS), and iron (III) chloride $\left(\mathrm{FeCl}_{3}\right)$ 
were purchased from Sigma-Aldrich (St. Louis, MO, USA). 1-(3-Dimethylaminopropyl)-3ethylcarbodiimide hydrochloride (EDC- $\mathrm{HCl}$ ) was purchased from Tokyo Chemical Industry (Tokyo, Japan). Phosphate-buffered saline (PBS, 10X, pH 7.2) was purchased from Welgene (Gyeongsan, Korea). Sodium chloride $(\mathrm{NaCl})$ was purchased from Daejung (Siheung, Korea). Anhydrous ethyl alcohol was purchased from Samchun Pure Chemical (Pyeongtaek, Korea). SpectraPor 1 Dialysis Membrane (Standard RC tubing, molecular weight cut-off $(\mathrm{MWCO})=6-8 \mathrm{kDa}$ ) was purchased from Spectrum (Rancho Dominguez, CA, USA).

\subsection{Synthesis and Characterization of Hyaluronic Acid-Catechol and Hyaluronic Acid-Tyramine Conjugates}

For the synthesis of HA-Ca, dopamine hydrochloride was conjugated with a sodium HA backbone by EDC/NHS coupling. HA (500 mg) was dissolved in $55 \mathrm{~mL}$ of MES buffer $(0.1 \mathrm{M}, \mathrm{pH} 4.6)$. The solution was stirred for $15 \mathrm{~min}$ under a nitrogen atmosphere to remove dissolved oxygen capable of triggering the oxidation of catechol. After HA was fully dissolved, $190 \mathrm{mg} / \mathrm{mL}$ EDC and $115 \mathrm{mg} / \mathrm{mL}$ NHS were separately dissolved in $1 \mathrm{~mL}$ of MES buffer (0.1 M, pH 4.6) and then added into the reaction solution using syringes. After $10 \mathrm{~min}, 190 \mathrm{mg}$ of dopamine hydrochloride dissolved in $2 \mathrm{~mL}$ MES buffer $(0.1 \mathrm{M}$, $\mathrm{pH}$ 4.6) was injected into the reaction solution using a syringe. The solution was stirred for $12 \mathrm{~h}$ at room temperature to facilitate the reaction, with a final $\mathrm{pH}$ of 5.5 for prevention of further oxidation of catechol groups. To remove any unreacted free molecules, dialysis was performed using a 6-8 $\mathrm{kDa}$ MWCO membrane in $5 \mathrm{~L}$ of $100 \mathrm{mM} \mathrm{NaCl}$ solution (dissolved in acidified deionized distilled water, $\mathrm{pH} 5$ ) for 2 days and then dialyzed in deionized distilled water for $4 \mathrm{~h}$. After dialysis, the solution was lyophilized for 6 days at $-80^{\circ} \mathrm{C}$, 5 mTorr. In addition, for the synthesis of HA-Ty, dopamine hydrochloride was conjugated with a sodium HA backbone by EDC/NHS coupling, following a previous report [24] and some adjustments were made. HA $(500 \mathrm{mg}$ ) was dissolved in $50 \mathrm{~mL}$ of MES buffer (0.1 M, pH 5.5). After HA was fully dissolved, $20.2 \mathrm{mg}$ of tyramine hydrochloride was added and stirred for $10 \mathrm{~min}$. Subsequently, $190 \mathrm{mg} / \mathrm{mL}$ EDC and $237 \mathrm{mg} / \mathrm{mL}$ NHS were added together. The $\mathrm{pH}$ was adjusted to 4.7 with $0.1 \mathrm{M} \mathrm{NaOH}$ for optimal amide coupling reaction. After overnight reaction with constant stirring at room temperature, dialysis was performed using a 6-8 $\mathrm{kDa}$ MWCO membrane in $5 \mathrm{~L}$ of $100 \mathrm{mM} \mathrm{NaCl}$ solution (dissolved in acidified deionized water (DW), pH 5) for 2 days, dialyzed with $25 \%$ ethanol for 2 days, and then dialyzed with DW for 1 day. After dialysis, the solution was lyophilized for 6 days at $-80{ }^{\circ} \mathrm{C}, 5 \mathrm{mTorr}$. The degree of catechol or tyramine substitution (DOS\%) was analyzed by both ${ }^{1} \mathrm{H}$ NMR spectroscopy ( $300 \mathrm{MHz}$; Varian, Palo Alto, CA, USA) and UV-vis spectroscopy (Agilent 8453; Agilent Technologies, Santa Clara, CA, USA). For obtaining ${ }^{1} \mathrm{H}$ NMR spectra, each polymer was dissolved in deuterium oxide $\left(\mathrm{D}_{2} \mathrm{O}\right)$ at a concentration of $10 \mathrm{mg} / \mathrm{mL}$. Additionally, for UV-vis spectra, the polymer solutions dissolved in DW were prepared at a concentration of $5 \mathrm{mg} / \mathrm{mL}$. The absorbance at the wavelength of $280 \mathrm{~nm}$ ( $\mathrm{A}_{280}$ for catechol) or $275 \mathrm{~nm}$ ( $\mathrm{A}_{275}$ for tyramine) was detected. The calibration curves were established using dopamine (the concentration ranging from $15.6 \mu \mathrm{g} / \mathrm{mL}$ to $62.5 \mu \mathrm{g} / \mathrm{mL}$ ) or tyramine (the concentration ranging from $3.9 \mu \mathrm{g} / \mathrm{mL}$ to $62.5 \mu \mathrm{g} / \mathrm{mL}$ ). Additionally, the sample purity was confirmed by diffusion ordered spectroscopy (DOSY) (Bruker, German).

\subsection{Preparation of Hydrogels}

\subsubsection{HRP-Induced HA-Ca and HA-Ty Hydrogels}

$\mathrm{HRP}$ was used as a biological oxidant for $\mathrm{H}_{2} \mathrm{O}_{2}$. To investigate the change in hydrogel properties based on the concentration of the oxidants, stock solutions of $\mathrm{H}_{2} \mathrm{O}_{2}$ $\left(0.5 \mathrm{mg} / \mathrm{mL}, 1 \mathrm{mg} / \mathrm{mL}\right.$, and $1.5 \mathrm{mg} / \mathrm{mL}$ in $\mathrm{pH} 6$ PBS for obtaining catechol (Ca): $\mathrm{H}_{2} \mathrm{O}_{2}$ molar ratios of 1:0.5, 1:1.0, 1:1.5, respectively) and HRP (2 unit $/ \mathrm{mL}, 6$ unit $/ \mathrm{mL}, 18$ unit $/ \mathrm{mL}$ to make 0.1 unit $/ \mathrm{mL}, 0.3$ unit $/ \mathrm{mL}$, and 0.9 unit $/ \mathrm{mL}$ hydrogel solution) were prepared. All hydrogels were $2 \mathrm{wt} \%$.

HRP-induced HA-Ca gel was prepared as follows. HA-Ca $(4 \mathrm{mg})$ was fully dissolved in $176 \mu \mathrm{L}$ of DW, $10 \mu \mathrm{L}$ of $\mathrm{HRP}$, and $10 \mu \mathrm{L}$ of $\mathrm{H}_{2} \mathrm{O}_{2}$ stock solution. After $12 \mathrm{~h}, 2 \mathrm{wt} \%$ 
HRP-induced HA-Ca gels were fabricated. HRP-induced HA-Ty gel was prepared using the same protocol, and HA-Ca was substituted with HA-Ty.

2.3.2. Detection of the Free Dopamine Not Involved in HRP-Induced HA-CA Hydrogels

HRP-induced HA-Ca hydrogel (HRP 0.9 unit/ $\mathrm{mL}$ and the molar ratio of $\mathrm{Ca}$ to $\mathrm{H}_{2} \mathrm{O}_{2}$, (1) was prepared as previous methods. The hydrogel was placed in transwell insert (24 well, $8 \mu \mathrm{m}$ pore, Corning) and exposed to $1 \mathrm{~mL}$ of DW. After $12 \mathrm{~h}$, the absorption spectra of the released sample solutions from the hydrogel were analyzed by UV-vis spectroscopy.

\subsubsection{Chemical Oxidant-Induced HA-Ca Hydrogels}

For triggering oxidative crosslinking of catechols, $\mathrm{NaOH}$ was used as a basic additive, and $\mathrm{NaIO}_{4}$ and APS were utilized as the chemical oxidants. To investigate the change in gel properties based on the concentration of the oxidants, stock solutions of $\mathrm{NaIO}_{4}\left(0.32 \mathrm{mg} / \mathrm{mL}, 1.6 \mathrm{mg} / \mathrm{mL}, 3.2 \mathrm{mg} / \mathrm{mL}, 9.6 \mathrm{mg} / \mathrm{mL}\right.$ for obtaining catechol: $\mathrm{NaIO}_{4}$ molar ratios of 10:1. 2:1. 1:1 and 1:3, respectively) and APS $(170 \mathrm{mg} / \mathrm{mL}, 340 \mathrm{mg} / \mathrm{mL}$, and $680 \mathrm{mg} / \mathrm{mL}$ to obtain molar ratios of Ca:APS molar ratios of 1:50, 1:100, and 1:200, respectively) were prepared. All hydrogels were $2 \mathrm{wt} \%$.

The $\mathrm{NaOH}$-induced HA-Ca hydrogel was prepared using the following steps. HA-Ca (4 mg) was fully dissolved in $190 \mu \mathrm{L}$ of DW, and the $\mathrm{pH}$ was adjusted by adding $6 \mu \mathrm{L}$ of $\mathrm{NaOH}$ solution. After $24 \mathrm{~h}$, hydrogels were prepared. The $\mathrm{NaIO}_{4}$-induced HA-Ca hydrogel was prepared using the following steps. HA-Ca $(4 \mathrm{mg})$ was fully dissolved in $176 \mu \mathrm{L}$ of $\mathrm{DW}$, and $20 \mu \mathrm{L}$ of $\mathrm{NaIO}_{4}$ stock solution was added to fabricate $\mathrm{NaIO}_{4}$-induced $\mathrm{HA}-\mathrm{Ca}$ gels. After $3 \mathrm{~h}$, the $\mathrm{NaIO}_{4}$-induced HA-Ca hydrogels were prepared. The APS-induced HA-Ca hydrogel was also prepared using the same protocol by substituting $\mathrm{NaIO}_{4}$ with APS. The APS-induced HA-Ty hydrogel was also prepared using the same protocol by substituting HA-Ca with HA-Ty.

\subsection{4. $\mathrm{FeCl}_{3}$-Induced HA-Ca Hydrogels}

To investigate the change in hydrogel properties based on the concentration of the oxidants, stock solutions of $\mathrm{FeCl}_{3}(2.0 \mathrm{mg} / \mathrm{mL}, 4.0 \mathrm{mg} / \mathrm{mL}$, and $8.0 \mathrm{mg} / \mathrm{mL}$ for obtaining $\mathrm{Ca}: \mathrm{Fe}^{3+}$ molar ratios of 2:1, 1:1, 1:2, respectively) were prepared. All hydrogels were $2 \mathrm{wt} \%$. For gelation, HA-Ca $(4 \mathrm{mg})$ was fully dissolved in $170 \mu \mathrm{L}$ of DW. Subsequently, $20 \mu \mathrm{L}$ of the specified concentration of $\mathrm{FeCl}_{3}$ solution was added and $6 \mu \mathrm{L}$ of $\mathrm{NaOH}$ solution was added to adjust the $\mathrm{pH}$. The gelation occurred after $18 \mathrm{~h}$.

\subsection{Morphological Analysis and Chemical Element Mapping of HA-Ca or HA-Ty Hydrogels}

To analyze cross-sectional morphology of the lyophilized HA-Ca or HA-Ty hydrogels, scanning electron microscopy (SEM; JSM7600F, Japan) equipped with an energy-dispersive X-ray spectroscopy (EDS) instrument was used.

\subsection{Rheological Characterization}

The rheological properties of the hydrogels were determined using a Discovery Hybrid Rheometer 2 (TA Instrument, New Castle, DE, USA) with a $20 \mathrm{~mm}$ parallel plate geometry and a gap size of $300 \mu \mathrm{m}$. The storage modulus $\left(\mathrm{G}^{\prime}\right)$ and loss modulus $\left(\mathrm{G}^{\prime \prime}\right)$ of the hydrogels as a function of the frequency $(0.1-10 \mathrm{~Hz})$ were performed at a strain of $1 \%$ at $25^{\circ} \mathrm{C}$. To test shear viscosity as a function of strain (From 0.01 to $100 \%$ ), HRP-induced HA-Ty hydrogels, HRP-induced HA-Ca hydrogels, and $\mathrm{FeCl}_{3}$-induced HA-Ca hydrogels were performed at $25{ }^{\circ} \mathrm{C}$.

\subsection{Compression Test}

To compare the morphologies of the HRP-induced HA-Ca hydrogel and HA-Ty hydrogel after compression, a compression test was performed. The method for preparing the hydrogel is described in Section 2.3.1. In addition, HRP-induced HA-Ca hydrogel (2 $\mathrm{wt} \%$ ) was prepared with the concentration of $0.9 \mathrm{unit} / \mathrm{mL} \mathrm{HRP}$ and $\mathrm{Ca}: \mathrm{H}_{2} \mathrm{O}_{2}$ molar 
ratio of 1:1 as a final concentration. HA-Ty hydrogel ( $200 \mathrm{mg}, 2 \mathrm{wt} \%)$ was also prepared with the same concentration of $\mathrm{HRP}$ and $\mathrm{H}_{2} \mathrm{O}_{2}$. After the preparation of the hydrogels, a weight of $700 \mathrm{~g}$ was placed on the gels to compress them for $10 \mathrm{~min}$. After the removal of the weight from the gels, the shapes before and after compression were compared.

\subsection{Swelling Behavior}

To examine the swelling kinetics of the HA-Ca and HA-Ty hydrogels crosslinked by $\mathrm{HRP} / \mathrm{H}_{2} \mathrm{O}_{2}$ catalyzed reaction (HRP 0.9 unit/mL and the molar ratio of $\mathrm{Ca}: \mathrm{H}_{2} \mathrm{O}_{2}, 1: 1$ ), each hydrogel was swollen in DW. At a pre-determined time interval $(0,0.5,1,2,4,8,16$, and $24 \mathrm{~h}$ ), we measured the weight of each hydrogel after removal of superficial moisture. The swelling ratio (\%) was calculated as the ratio of swollen weight of hydrogel to their initial weight. All experiments were triplicate.

\subsection{Chemical Analysis of HA-Ca Crosslinking Depending on Oxidative Pathway}

For investigating HA-Ca crosslinking chemistry, UV-vis spectroscopy data were collected. The method for preparing the hydrogel is described in Section 2.3.2 of this report, except for the incubation time. To obtain UV-vis spectrum data, solutions were prepared under the condition that color changes but does not form a hydrogel or color changes but before gelation time. Therefore, the $\mathrm{NaOH}$-induced HA-Ca hydrogel ( $\mathrm{pH}$ 12) was prepared with an incubation time of $4 \mathrm{~h}$. $\mathrm{NaIO}_{4}$-induced HA-Ca hydrogel (Ca: $\mathrm{NaIO}_{4}$ molar ratio of 1:3) was prepared with an incubation time of $12 \mathrm{~h}$. APS-induced HA-Ca hydrogel (Ca:APS molar ratio of 1:200) was prepared with an incubation time of $30 \mathrm{~min}$. HRP-induced HA-Ca hydrogel ( 0.3 unit/mL of HRP, Ca: $\mathrm{H}_{2} \mathrm{O}_{2}$ molar ratio of 1:1) was prepared with an incubation time of $11 \mathrm{~h}$. UV-vis spectra were recorded using an Agilent 8453 UV-vis spectrometer (Agilent Technologies, Santa Clara, CA, USA).

\subsection{Adhesion Strength Characterization of the Hydrogels}

Tensile adhesion of the hydrogels was determined using a universal testing machine (34SC-1, Instron, IL, USA). The substrate was prepared using $30 \mathrm{~mm} \times 10 \mathrm{~mm} \times 0.1 \mathrm{~mm}$ and PET film. The samples were placed between two substrates and pressed with a weight of $1 \mathrm{~kg}$ for $15 \mathrm{~min}$. The overlapped area was $10 \mathrm{~mm} \times 10 \mathrm{~mm}$, and the crosshead speed was $20 \mathrm{~mm} / \mathrm{min}$. Each sample test was repeated five times.

\subsection{Degradation Test}

To investigate degradation profile of the HA-Ca hydrogels, we prepared the hydrogels crosslinked using three different oxidation methods, such as gelation in basic condition $(\mathrm{pH} 10)$ and under treatment of $\mathrm{NaIO}_{4}$ or APS. For gelation triggered by either $\mathrm{NaIO}_{4}$ or APS, the molar ratio of catechol to each oxidant as 1 to 1 for $\mathrm{NaIO}_{4}$ and 1 to 100 for APS was utilized. After 0 (initial hydrogels) or $24 \mathrm{~h}$ of swelling in DW, these hydrogels were lyophilized over $12 \mathrm{~h}$ at $-80{ }^{\circ} \mathrm{C}$, and then the weight of dried samples was measured. Finally, the degradation (\%) was calculated by the weight changes after soaking in DW compared to initial sample weight.

\subsection{Statistical Analysis}

All statistically analyzed data were determined using Student's unpaired $t$-test. Statistically significant differences were considered when the $p$-value was less than 0.05 .

\section{Results and Discussion}

\subsection{Preparation of HA-Ca and HA-Ty Polymers and Cohesion Properties of HRP-Induced Each Hydrogel}

To synthesize the desired hydrogels, modified HA was initially prepared and characterized HA was individually conjugated with catechol and tyramine to obtain HA-Ca and HA-Ty, respectively. The two modified HAs, HA-Ca and HA-Ty, were synthesized via the EDC/NHS coupling reaction (Supplementary Figure S1a,b). For HA-Ca, the DOS\% 
of catechol was $3.7 \%$, which was calculated by integral values of protons in aromatic rings of catechol compared to protons of HA backbone in ${ }^{1} \mathrm{H}$ NMR spectra. Additionally, the DOS $\%$ analyzed by UV-vis spectra was $4.0 \%$, like that of ${ }^{1} \mathrm{H}$ NMR result. For HA$\mathrm{Ty}$, the DOS\% of tyramine was $4.6 \%$ from ${ }^{1} \mathrm{H}$ NMR spectroscopy and $4.5 \%$ from UV-vis spectroscopy (Figure 2a,b). When the catechol is tethered on polysaccharide, a few free catechol derivatives can be intercalated among the polymeric chains due to their intrinsic adhesiveness [24]. As shown in the results of DOSY (Supplementary Figure S1c,d), all proton signals in HA-Ty showed similar diffusion velocity $\left(\sim 10^{-12} \mathrm{~m}^{2} / \mathrm{s}\right)$, which indicates high purity of the polymer without free tyramine molecules (Supplementary Figure S1c). In contrast, a part of proton signals in HA-Ca exhibited fast diffusion behavior $\left(\sim 10^{-10} \mathrm{~m}^{2} / \mathrm{s}\right)$ (red dashed box, Supplementary Figure S1d), referring a certain degree of free dopamine entrapped in the polymer. For quantitative analysis of the free dopamine, we examined the dopamine amount not involved in gelation (e.g., HRP-triggered HA-Ca hydrogels) using UV-vis spectroscopy. As a result, $0.75 \%$ of free dopamine in total $\sim 4$ DOS\% was present in the gels (Supplementary Figure S2), which might be low not to significantly affect cohesive and adhesive strength of the hydrogels. Considering similar DOS\% in both HA-Ca and HA-Ty, the polymers were utilized for further gelation to compare the cohesion and adhesion properties by each polyphenol (Supplementary Figure S2).

\section{(a)}

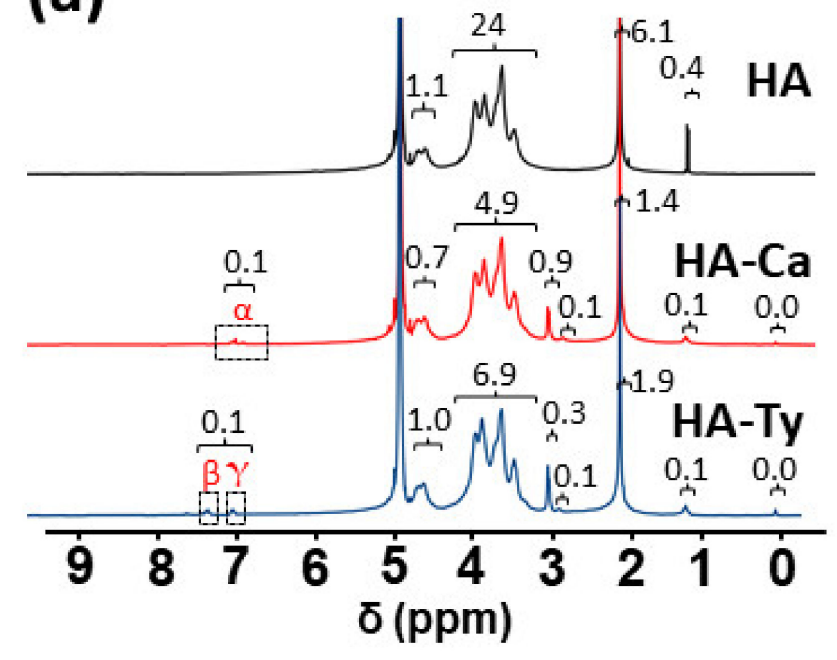

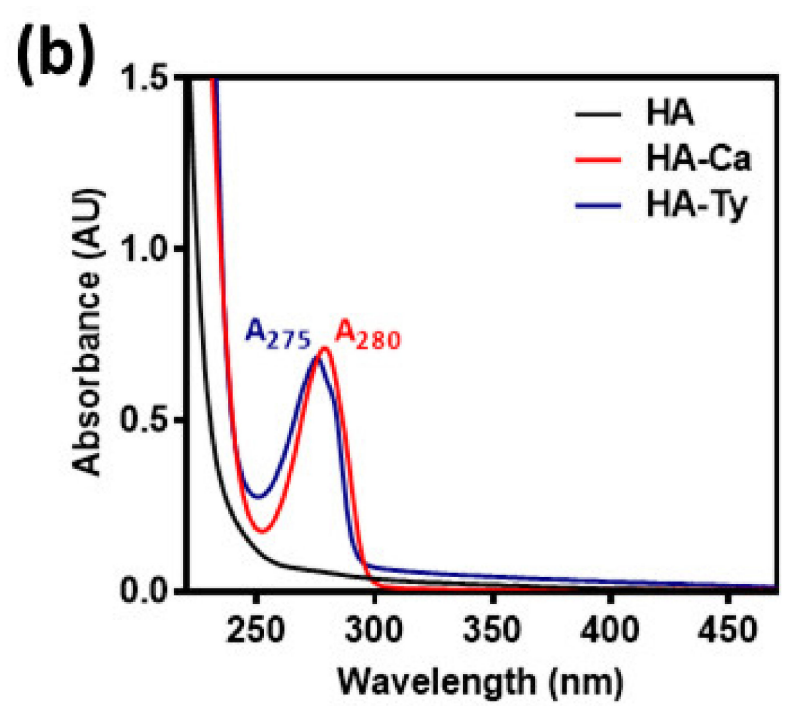

Figure 2. Characterization of HA-Ca and HA-Ty conjugates to evaluate degree of polyphenol substitution (\%) on the HA backbone. (a) ${ }^{1} \mathrm{H}$ NMR spectrum of HA (black), HA-Ca (yellow), and HA-Ty (blue). The ' $\alpha$ ' protons indicate the protons adjacent to two hydroxyl groups in catechol moieties. The ' $\beta$ and $\gamma$ ' protons indicate the protons adjacent to hydroxyl group in tyramine moieties. (b) UV-vis spectra of HA (black), HA-Ca (red), and HA-Ty (blue) solutions. The absorbance at the wavelength of $280 \mathrm{~nm}\left(\mathrm{~A}_{280}\right)$ means the presence of catechol, and the absorbance at $275 \mathrm{~nm}\left(\mathrm{~A}_{275}\right)$ indicates tyramine.

Each HA-Ca or HA-Ty hydrogel was obtained upon addition of $\mathrm{HRP}$ and $\mathrm{H}_{2} \mathrm{O}_{2}$ into the modified HA solutions, causing di-catechol and di-tyramine crosslinking in each solution (Figure 3a) [25,26]. During such crosslinking reaction, di-catechol and di-tyramine bonds form the HA polymeric network (e.g., hydrogels) with different color appearances. Before gelation, both HA-Ca and HA-Ty solutions were initially transparent; however, after gelation, the HA-Ca hydrogel had an observable reddish-brown hue, whereas HATy hydrogels remained transparent (Figure $3 b$ ). This might result from the formation of di-catechol (Supplementary Figure S3) [27]. In addition, for morphological analysis of each hydrogel, the cross-sectional images and chemical element mapping of the dried hydrogels were observed by SEM and EDS, respectively (Supplementary Figure S4). Both hydrogels exhibited typical microporous structures with $\sim 40 \mu \mathrm{m}$ of pores, and all elements (e.g., carbon, nitrogen, and oxygen of each polymer) were distributed in the overall area. 
(a)

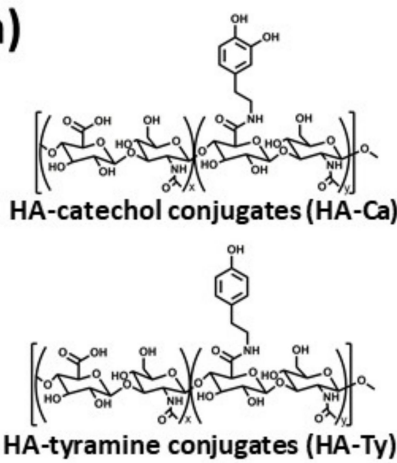

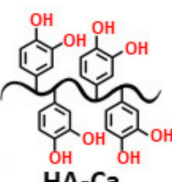

HA-Ca

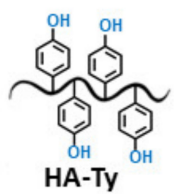

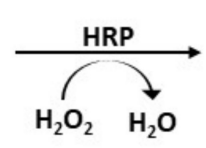

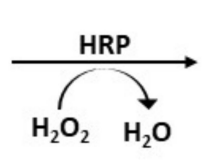

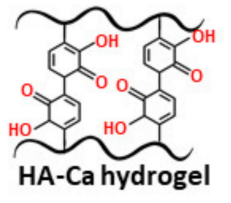

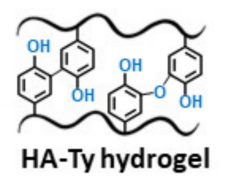

(c)

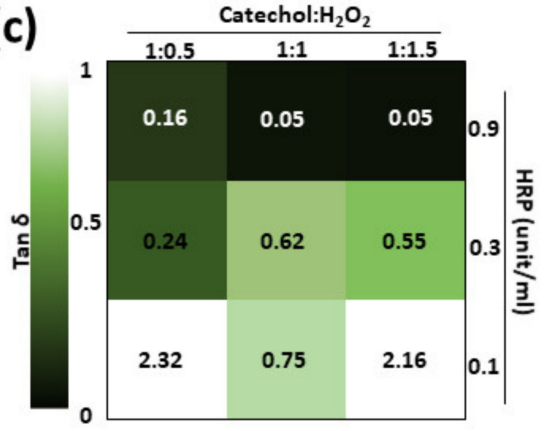

(f)

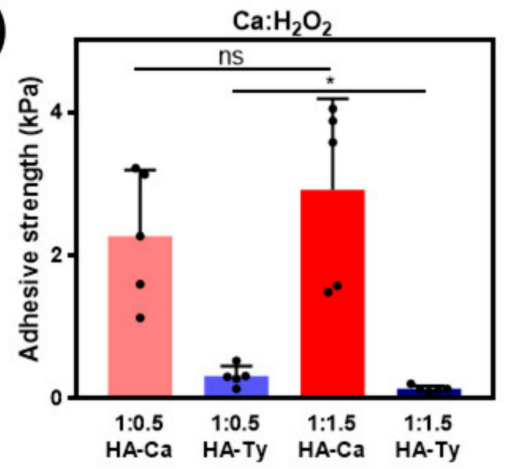

(d)

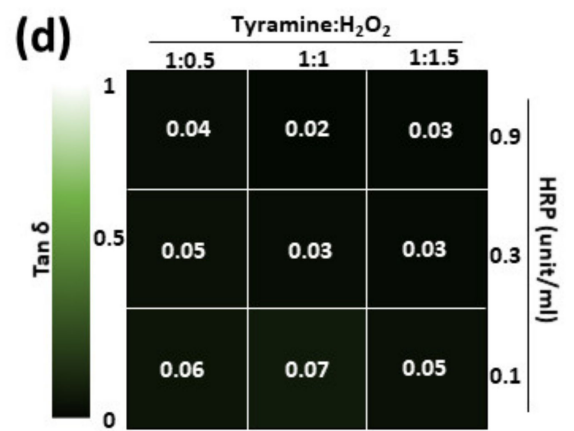

(g)

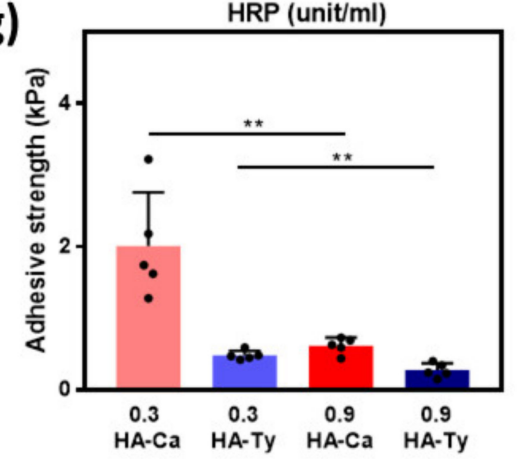

(b)

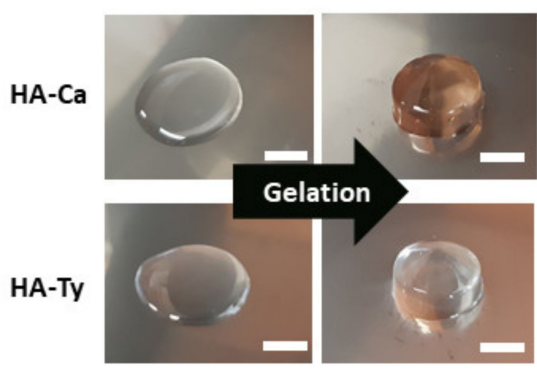

(e)

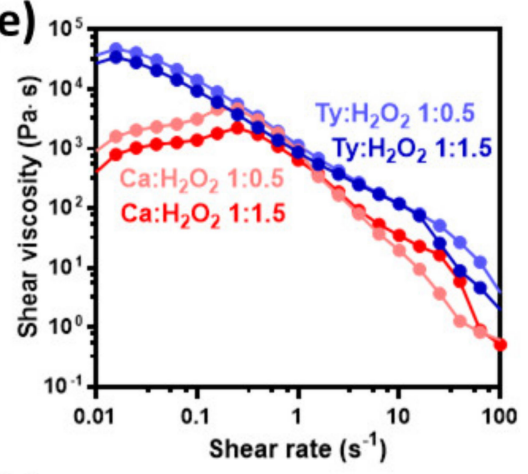

(h)

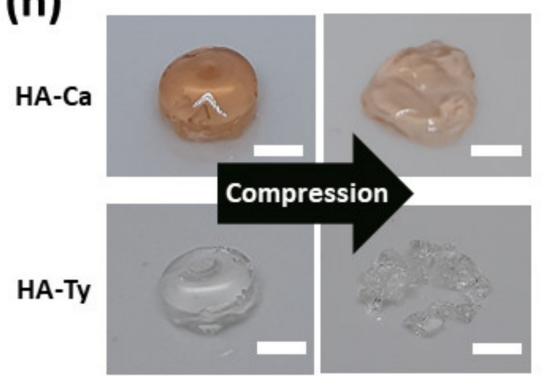

Figure 3. Comparative observation of HA-Ca and HA-Ty hydrogel which are crosslinked by biological oxidants. (a) HA-Ca (top) and HA-Ty (bottom) are crosslinked by horseradish peroxidase (HRP) and hydrogen peroxide $\left(\mathrm{H}_{2} \mathrm{O}_{2}\right)$ to form $\mathrm{HA}-\mathrm{Ca}$ and HA-Ty hydrogel, respectively. (b) Gelation of HA-Ca solution (top) and HA-Ty solution (bottom) before (left) and after gelation (right) (scale bar $=5 \mathrm{~mm}$ ). Rheological properties of (c) HA-Ca and (d) HA-Ty hydrogels with different HRP and $\mathrm{H}_{2} \mathrm{O}_{2}$ concentrations. (e) Shear viscosity of HA-Ca (reddish) and HA-Ty (bluish) as a function of shear rate in different ratios of $\mathrm{H}_{2} \mathrm{O}_{2}$ showing a shear-thinning property. Adhesion strength of HA-Ca and HA-Ty hydrogels in (f) different $\mathrm{H}_{2} \mathrm{O}_{2}$ molar ratio at $0.3 \mathrm{unit} / \mathrm{mL}$ of HRP concentration and $(\mathrm{g})$ different concentrations of $\mathrm{HRP}$ at $\mathrm{H}_{2} \mathrm{O}_{2}$ molar ratio of 1:1 ( $n=5$, mean $\pm \mathrm{SD})\left({ }^{*} p<0.05,{ }^{* *} p<0.01, \mathrm{~ns}=\right.$ not significant). (h) Images of HA-Ca hydrogel (top) and HA-Ty hydrogel (bottom) before (left) and after (right) compression (scale bar $=5 \mathrm{~mm}$ ).

Furthermore, the resulting HA-Ca hydrogels and HA-Ty hydrogels showed comparatively different storage moduli and $\tan \delta$ values. HA-Ca hydrogels with different HRP concentrations (from 0.1 to $0.9 \mathrm{unit} / \mathrm{mL}$ ) and different molar ratios of catechol to $\mathrm{H}_{2} \mathrm{O}_{2}$ (from 1:0.5 to 1:1.5) were compared to HA-Ty hydrogels prepared in the same condition. At the beginning of the study, we described a hydrogel with a $\tan \delta \leq 0.05$ as being stiff. As regards the HA-Ca hydrogel that contained less than 0.1 unit/mL concentration of HRP, a negligible difference existed in the storage modulus and tan $\delta$ owing to its inability to form a stable hydrogel structure. By increasing the concentration, hydrogels with a concentration of over $0.3 \mathrm{unit} / \mathrm{mL}$ resulted in an HA-Ca hydrogel with biological activity. HA-Ca formed hydrogels when the concentration of HRP was 0.3 unit/mL. However, when the molar ratio of $\mathrm{H}_{2} \mathrm{O}_{2}$ is increased, a softer hydrogel is formed. This implies that 
when the concentration of $\mathrm{H}_{2} \mathrm{O}_{2}$ exceeds an optimum ratio, excess $\mathrm{H}_{2} \mathrm{O}_{2}$ will interfere with hydrogel formation rather than supporting it.

When the HRP concentration is over $0.9 \mathrm{unit} / \mathrm{mL}$, it provides conditions that are adequate for HA-Ca to form stiff hydrogels. A significant observation based on these measurements is that the minimum ratio of $\mathrm{H}_{2} \mathrm{O}_{2}(1: 1$ molar ratio and $\mathrm{HRP} 0.9$ unit $/ \mathrm{mL})$ must be obtained to create a stiff hydrogel in $\mathrm{HA}-\mathrm{Ca}\left(\tan \delta=0.05\right.$ and $\mathrm{G}^{\prime}=290 \mathrm{~Pa}$ at $\left.1 \mathrm{~Hz}\right)$. Figure $3 \mathrm{c}$ shows that when the concentration of $\mathrm{H}_{2} \mathrm{O}_{2}$ was 1:0.5, even though HRP content was 0.9 unit $/ \mathrm{mL}$, it still failed to show stiff hydrogel formation $\left(\tan \delta=0.16\right.$ and $\mathrm{G}^{\prime}=93 \mathrm{~Pa}$ at $1 \mathrm{~Hz}$ ). Stiff hydrogels were present in HA-Ca only when the HRP concentration was 0.9 unit $/ \mathrm{mL}$ and the $\mathrm{H}_{2} \mathrm{O}_{2}$ concentration was either 1:1 and 1:1.5. This reaction occurs for two reasons: (i) the larger quantity of $\mathrm{H}_{2} \mathrm{O}_{2}$ and $\mathrm{HRP}$ resulted in a higher degree of crosslinking in the hydrogel, and (ii) no $\mathrm{H}_{2} \mathrm{O}_{2}$ remained in the hydrogel, preventing it from interfering in the hydrogel formation (Figure 3d, Supplementary Figure S5). The HA-Ca and HA-Ty hydrogels crosslinked by HRP reaction had different cohesion properties, which correspond to different crosslinking density. For details, the HA-Ty hydrogels possess much higher crosslinking ratio than that of HA-Ca, affecting their swelling kinetics [28]. To demonstrate this, we checked the swelling kinetics of each hydrogel as a function of time. As shown in Supplementary Figure S6, the HA-Ca hydrogels showed higher swelling ratio (398\% after 8-h incubation) than that of HA-Ty (1230\% after 8-h incubation).

To compare the shear thinning property, shear viscosity was observed based on the shear rate. Shear thinning is crucial for 3D bioprinting and injection using syringes. Both HA-Ca and HA-Ty hydrogels exhibited shear viscosities similar to those of the HA-Ty hydrogel when the shear rate is over $0.25 \mathrm{~s}^{-1}$. Under $0.25 \mathrm{~s}^{-1}, \mathrm{HA}-\mathrm{Ca}$ showed shear thickening, whereas HA-Ty showed shear-thinning properties (Figure 3e).

\subsection{Adhesion Properties of HRP-Induced HA-Ca and HA-Ty Hydrogels}

To verify the correlation between cohesion and adhesion strength, a versatile molar ratio of $\mathrm{H}_{2} \mathrm{O}_{2}$ was used to fabricate hydrogels, and the concentration of HRP was fixed at $0.3 \mathrm{unit} / \mathrm{mL}$. We hypothesized that the stronger cohesion is induced by the greater number of phenol moieties used for crosslinking, which would decrease the adhesion properties. In previous studies, $\mathrm{HA}-\mathrm{Ca}$ and $\mathrm{HA}-\mathrm{Ty}$ made with a 1:0.5 $\mathrm{H}_{2} \mathrm{O}_{2}$ molar ratio showed a higher storage modulus $\left(\mathrm{G}^{\prime}=47 \mathrm{~Pa}\right.$ at $\mathrm{HA}-\mathrm{Ca}$ hydrogel, $\mathrm{G}^{\prime}=3,172 \mathrm{~Pa}$ at HA-Ty hydrogel) than 1:1.5 ( $\mathrm{G}^{\prime}=21 \mathrm{~Pa}$ at HA-Ca hydrogel, $\mathrm{G}^{\prime}=1446 \mathrm{~Pa}$ at HA-Ty hydrogel) (Tables 1 and 2). However, the result did not show significant differences because the difference in concentration of $\mathrm{H}_{2} \mathrm{O}_{2}$ was not significant. This shows that the structural differences between crosslinked catechol and tyramine cause differences in the adhesion strength of the hydrogel (Figure 3f).

Table 1. Storage modulus $\left(\mathrm{G}^{\prime}\right)$ of HA-Ca hydrogels at different HRP concentrations and the stoichiometric ratio of $\mathrm{H}_{2} \mathrm{O}_{2}$ to $0.5,1$, or 1.5 .

\begin{tabular}{cccc}
\hline $\mathbf{G}^{\prime}(\mathbf{P a})$ & $\mathbf{H}_{\mathbf{2}} \mathbf{O}_{\mathbf{2}} \mathbf{1 : 0 . 5}$ & $\mathbf{H}_{\mathbf{2}} \mathbf{O}_{\mathbf{2}} \mathbf{1 : 1}$ & $\mathbf{H}_{\mathbf{2}} \mathbf{O}_{\mathbf{2}} \mathbf{1 : 1 . 5}$ \\
\hline $\mathrm{HRP} 0.3$ unit $/ \mathrm{mL}$ & 93 & 290 & 205 \\
$\mathrm{HRP} 0.9$ unit/mL & 47 & 18 & 21 \\
\hline
\end{tabular}

Table 2. Storage modulus $\left(\mathrm{G}^{\prime}\right)$ of HA-Ty hydrogels at different HRP concentrations and the stoichiometric ratio of $\mathrm{H}_{2} \mathrm{O}_{2}$ to $0.5,1$, or 1.5 .

\begin{tabular}{cccc}
\hline $\mathbf{G}^{\prime}(\mathbf{P a})$ & $\mathbf{H}_{\mathbf{2}} \mathbf{O}_{\mathbf{2}} \mathbf{1 : 0 . 5}$ & $\mathbf{H}_{\mathbf{2}} \mathbf{O}_{\mathbf{2}} \mathbf{1 : 1}$ & $\mathbf{H}_{\mathbf{2}} \mathbf{O}_{\mathbf{2}} \mathbf{1 : 1 . 5}$ \\
\hline $\mathrm{HRP} 0.3 \mathrm{unit} / \mathrm{mL}$ & 5146 & 4736 & 4305 \\
$\mathrm{HRP} 0.9$ unit/mL & 3172 & 1551 & 1446 \\
\hline
\end{tabular}

To obtain the adhesion strength, a lap-shear test was performed. When the concentration of $\mathrm{H}_{2} \mathrm{O}_{2}$ was fixed at a 1:1 molar ratio while changing the concentration of HRP, the results supported our initial hypothesis, where an increase in the degree of crosslinking 
in the hydrogel will result in a correlative decrease in the adhesion strength. The HA-Ca hydrogel resulted in a stronger adhesion strength at $0.3 \mathrm{unit} / \mathrm{mL}$ of HRP concentration of 0.9 unit/mL. Moreover, 0.3 unit/mL HRP-induced HA-Ca gel showed low G' (18 Pa) compared to $0.9 \mathrm{unit} / \mathrm{mL}$ HRP-induced HA-Ca hydrogel $\left(\mathrm{G}^{\prime}=290 \mathrm{~Pa}\right)$. This indicates that the cohesion becomes strong owing to more crosslinking, and the adhesion becomes weak (Figure 3g, Table 1). In addition, because of their crosslinking structure, HA-Ca and HA-Ty had different deformation shapes. When a weight of $700 \mathrm{~g}$ was applied to the gel for $10 \mathrm{~min}$, HA-Ca showed plastic deformation, but HA-Ty was ruptured. This unexpected result might be attributed to the different structures of HA-Ca and HA-Ty being ruptured. This result can also be attributed to the different structures of HA-Ca and HA-Ty after crosslinking. This is because the HA-Ca hydrogel has one carbonyl group and two hydroxyl groups, which can exhibit adhesive properties via hydrogen bonding. Thus, HA-Ca interacts with each other through non-covalent bonding. They can lump together, even after compression (Figure $3 \mathrm{~h}$ ). These adhesion properties were supported by previous adhesion tests (Figure 3f,g).

\subsection{Cohesion Properties of Chemical Oxidant-Induced HA-Ca Hydrogels}

Previous studies have suggested several chemical oxidants, such as $\mathrm{NaIO}_{4}$, and APS, which can oxidize and crosslink catechol moieties. In addition, the basic condition (e.g., $\mathrm{NaOH}$ ) can induce di-catechol crosslinking. To investigate the effect of the oxidants, the rheological properties of each oxidizing agent were investigated. These oxidants are known to convert catechol into di-catechol (Figure 4a) [29,30]. However, the colors of the prepared hydrogels were different. The differences were verified using UV-vis spectroscopy and photographic images. HA-Ca hydrogels prepared in $\mathrm{NaOH}$ appeared a deep brown color with an absorption peak at $325 \mathrm{~nm}$. This peak is observed when semi-quinone is generated, and it can initiate di-catechol crosslinking [31]. The hydrogel induced by APS was bright yellow and had a narrow absorption peak at $400 \mathrm{~nm}$. This peak indicates the quinone form generated by the oxidation of catechol which initiates di-catechol, similar to semiquinone [32]. The hydrogel with $\mathrm{NaIO}_{4}$ showed a slightly yellowish hue with a broad absorption peak at $425 \mathrm{~nm}$. This peak indicates the formation of di-catechol (Figure 4a,b) [33].

Variable crosslinking density can be achieved by tuning the number of oxidants. However, in the case of $\mathrm{NaOH}$, the data are expressed as $\mathrm{pH}$ instead of the amount of $\mathrm{NaOH}$. When the $\mathrm{pH}$ was increased from 5 to 9, HA-Ca formed a hydrogel (storage modulus > loss modulus), which indicated that the cohesive ability increased with an increase in $\mathrm{pH}$. However, as the $\mathrm{pH}$ exceeded a certain level, the hydrogel did not form $\left(\mathrm{G}^{\prime}<\mathrm{G}^{\prime \prime}\right.$ at $\left.\mathrm{pH} 12\right)$. This weakening of the cohesive ability is likely caused by heterogeneous gelation induced by an excessively high $\mathrm{pH}$ (Figure 4c).

Compared to the hydrogel with $\mathrm{NaOH}$, the hydrogel with APS was more elastic. The APS-added HA-Ca showed elastic hydrogel (Ca:APS was 1:100 and 1:200) when the molar ratio was above 1:50. This suggests that the cation $-\pi$ interaction helps to form a stiff hydrogel. (Figure 4c,d) [34]. In addition, APS induced a transparent HA-Ty hydrogel. Tyramine is known to be crosslinked in the presence of an enzyme catalyst such as HRP, and hydrogel formation of a polymer-tyramine conjugate induced by APS has not been reported. This unexpected result also suggests that the $\pi$-cation interaction may promote the cohesive properties of hydrogels, unlike other chemical oxidants (Supplementary Figure S7). The $\mathrm{NaIO}_{4}$ added HA-Ca hydrogel acts similar to NaOH. Furthermore, as the molar ratio of $\mathrm{Ca}: \mathrm{NaIO}_{4}$ was increased from 10:1 to 1:1, the cohesive ability of the solution increased, eventually leading to the formation of the hydrogel at a 1:1 molar ratio $\left(G^{\prime}>G^{\prime \prime}\right)$. However, as the molar ratio of $\mathrm{NaIO}_{4}$ is further increased, the cohesive ability decreases, which is similar to $\mathrm{NaOH}$, where the weakening of its cohesive ability is caused by the aforementioned heterogeneous gelation (Figure 4e).

Meanwhile, such chemical oxidants (e.g., $\mathrm{NaOH}$ ) can degrade $\mathrm{HA}$ backbone $[35,36]$. According to the results, to evaluate the recovered dry weight of HA-Ca after swelling of 
$24 \mathrm{~h}$ (Supplementary Figure S8), the degree of degradation was 20\% for $\mathrm{NaOH}$-induced $\mathrm{HA}-\mathrm{Ca}, \sim 11 \%$ for APS-induced one, and less than $\sim 2 \%$ for the $\mathrm{NaIO}_{4}$-induced one. That is, a certain degree of HA backbone can be degraded by those chemical oxidants, yet it was approximately less than only $20 \%$ of total hydrogel weights.

(a)

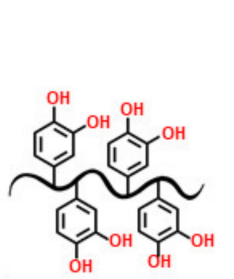

HA-Ca

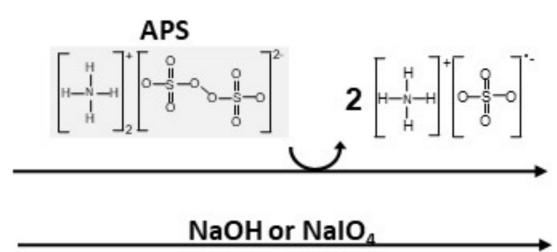

$\mathrm{NaOH}$ or $\mathrm{NalO}$

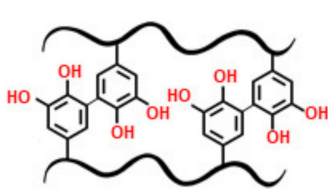

HA-Ca hydrogel (b)

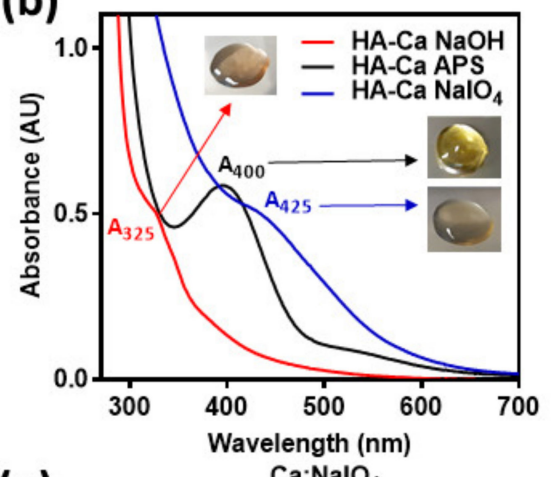

(c)

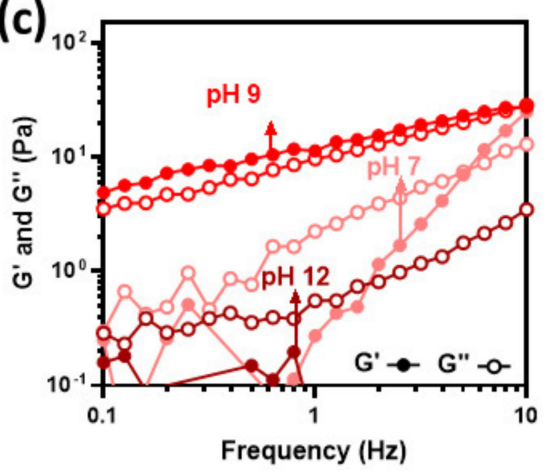

(f)

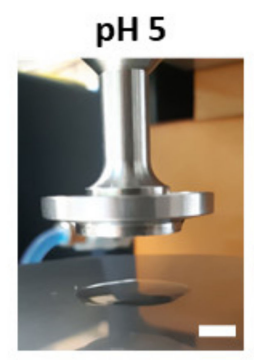
pH 9

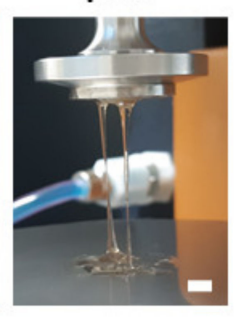

(d)

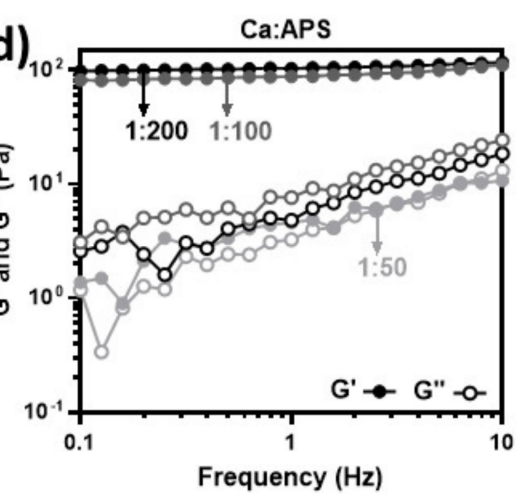

(g)

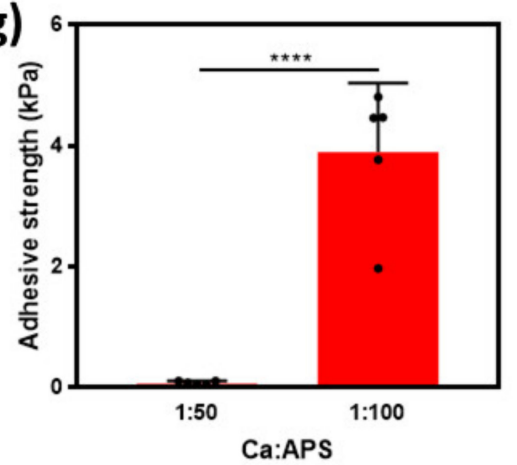

(e) $\mathrm{Ca}: \mathrm{NaIO}_{4}$

(h)
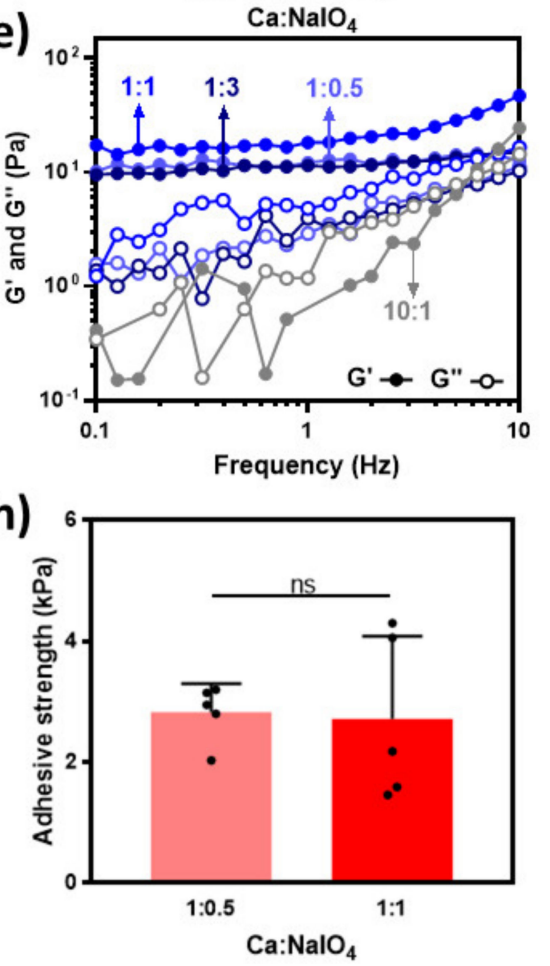

Figure 4. Adhesive and cohesive properties of chemical oxidants-induced hydrogels. (a) Catechol forms di-catechol covalent bonds owing to APS, $\mathrm{NaIO}_{4}, \mathrm{NaOH}$. (b) UV-vis spectra of chemical crosslinking-induced HA-Ca solutions by three different oxidants. Frequency sweep-storage $\left(\mathrm{G}^{\prime}\right)$ and loss $\left(\mathrm{G}^{\prime \prime}\right)$ moduli of HA-Ca hydrogels at $1 \%$ strain, oxidized with $(\mathbf{c}) \mathrm{NaOH}$, (d) $\mathrm{NaIO}_{4}$, and (e) APS with different molar ratios of catechol and the oxidant. (f) Images of $\mathrm{NaOH}$-induced hydrogel with different $\mathrm{pH}$ (scale bar $=5 \mathrm{~mm}$ ). Adhesion strength of various oxidants-induced HA-Ca hydrogels on PET substrate in (g) different Ca:APS molar ratio and (h) different $\mathrm{Ca}: \mathrm{NaIO}_{4}$ molar ratio $(n=5$, mean $\pm \mathrm{SD})\left({ }^{* * * *} p<0.0001\right.$, ns $=$ not significant).

\subsection{Adhesion Properties of Chemical Oxidant-Induced HA-Ca Hydrogels}

Because $\mathrm{NaOH}$-induced hydrogels were formed at a $\mathrm{pH}$ of 7 , the comparison of different $\mathrm{pH}$ conditions of the hydrogel was impossible. Therefore, adhesion strength was tested only for APS-induced hydrogels and $\mathrm{NaIO}_{4}$-induced hydrogels, and the stickiness according to the $\mathrm{pH}$ change is shown in Figure $4 \mathrm{f}$. Stickiness increasingly appeared at $\mathrm{pH} 7$ compared to $\mathrm{pH}$ 5. In the case of APS-induced hydrogels, two APS molar ratios (1:50 and 1:100) were tested. A molar ratio of 1:100 showed higher adhesion strength $(3.9 \pm 0.5 \mathrm{kPa})$ than that of 1:50 $(0.08 \pm 0.0 \mathrm{kPa})$. The reason for this result is that gel formation is difficult 
at a ratio of 1:50, which means the phase is almost same as liquid. This means that adhesive force did not appear if no minimal cohesive force existed (Figure $4 \mathrm{~g}$ ).

In the case of the $\mathrm{NaIO}_{4}$-induced HA-Ca hydrogel, the 1:0.5, and 1:1 molar ratio of Ca: $\mathrm{NaIO}_{4}$ did not show significant differences in adhesion strength. This is because the difference in $\mathrm{G}^{\prime}$ (12 Pa at 1:1 molar ratio, $18 \mathrm{~Pa}$ at 1:0.5, molar ratio) is not large; thus, the degree of crosslinking was not significantly different (Figure $4 \mathrm{~h}$ ).

\subsection{Cohesion Properties of $\mathrm{Fe}^{3+}$-Induced HA-Ca Hydrogels}

Catechol interacts with ferric $\left(\mathrm{Fe}^{3+}\right)$ ions via coordination bonds to form mono-, bis-, and tri-complexes. Based on the $\mathrm{pH}$, this catechol- $\mathrm{Fe}^{3+}$ ion complexation can form mono-, bis-, and tris complexes (Figure 5a) [37]. In addition, bis and tri complexes increase cohesion strength because they can grab onto other polymers. At $\mathrm{pH} 5$ and 7 , the hydrogels have an observable dark green hue and a brown hue at $\mathrm{pH} 10$. This brown color indicates the formation of a tri complex (Figure 5b) [38].

(a)

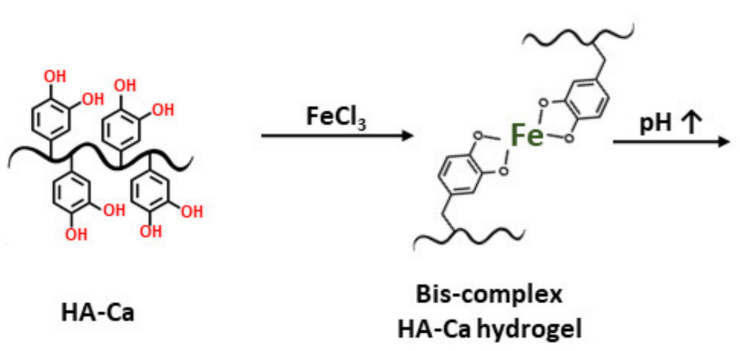

(b)

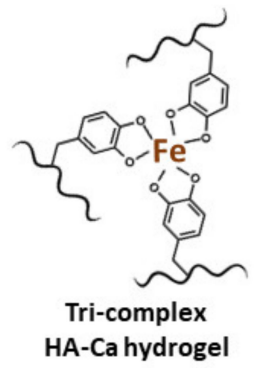

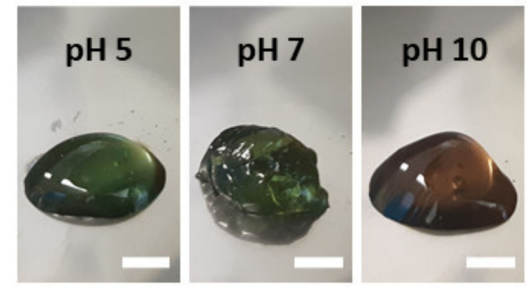

(e)

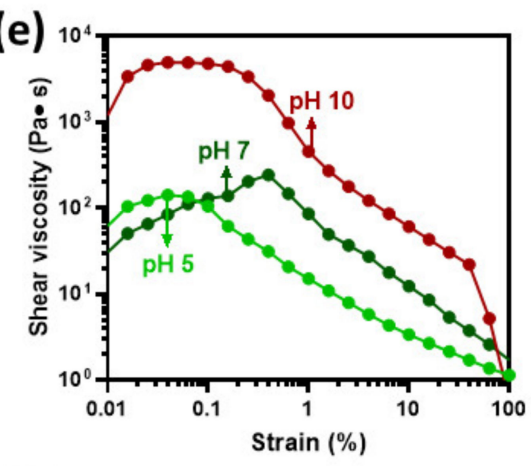

(h)

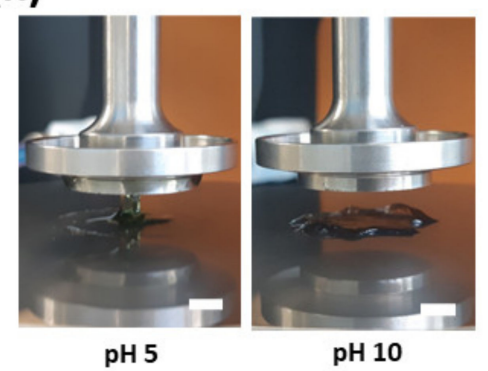

(c)

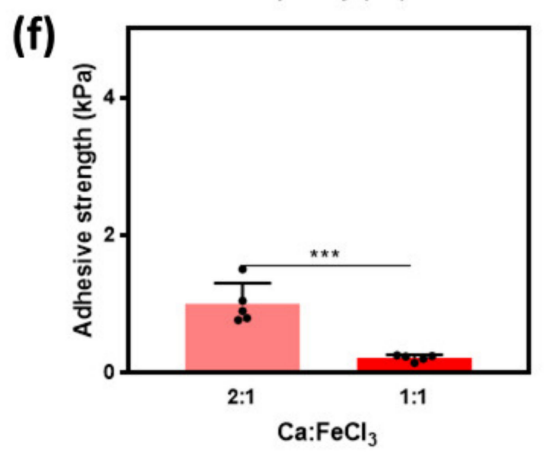

(d)

(g)

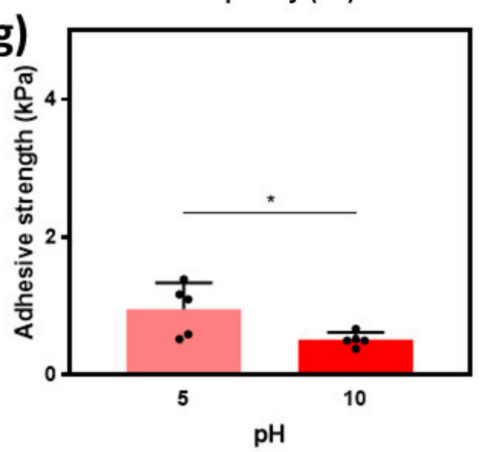

$\mathrm{pH}$

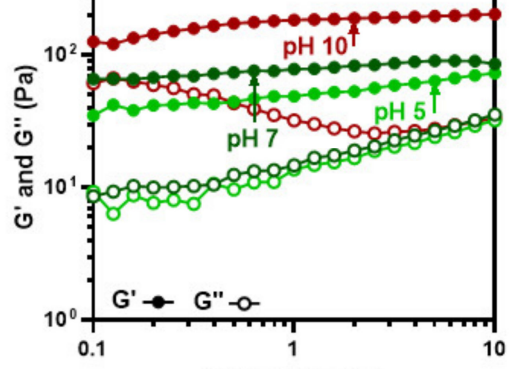

Figure 5. Adhesive and cohesive properties of $\mathrm{FeCl}_{3}$-induced hydrogels. (a) Catechol forms a non-covalent coordination bond owing to $\mathrm{Fe}^{3+}$ ion. (b) Photos of $\mathrm{FeCl}_{3}$-induced $\mathrm{HA}-\mathrm{Ca}$ hydrogel prepared at different $\mathrm{pH}(5,7$, and 10$)$ (scale bar $=5 \mathrm{~mm}$ ). (c) in different $\mathrm{pH}$ at $\mathrm{Ca}: \mathrm{Fe}^{3+}$ molar ratio of 2:1 and (d) in different $\mathrm{Fe}^{3+}$ molar ratios at $\mathrm{pH}$ 7. (e) Shearthinning properties of the hydrogel in different $\mathrm{pH}$ at $\mathrm{Ca}: \mathrm{Fe}^{3+}$ molar ratio of 2:1. Adhesion strength of the hydrogels in (f) different catechol: $\mathrm{Fe}^{3+}$ molar ratios at $\mathrm{pH} 7,(\mathrm{~g})$ different $\mathrm{pH}$ at $\mathrm{Ca}: \mathrm{Fe}^{3+}$ molar ratio of 2:1 $(n=5$, mean $\pm \mathrm{SD})\left({ }^{*} p<0.05\right.$, *** $p<0.001$ ), and (h) their images at pH 5 (left) and pH 10 (right) (scale bar $=5 \mathrm{~mm}$ ). 
To tune the crosslinking density, the HA-Ca solution was crosslinked with a variable amount of $\mathrm{Fe}^{3+}$ ions. The molar ratio of catechol and $\mathrm{Fe}^{3+}$ ions was modulated (2:1, 1:1, and 1:2) while fixing the $\mathrm{pH}$ to 7 . Among the three conditions, a 1:1 concentration is where the cohesion strength was the highest. This result might be contrary to previous reports [22] in which a ratio of 2:1 can completely form bis-complexes. A possible explanation is that the distance between catechol is too far for crosslinking between them to properly form, thus a higher concentration of mono complex instead of bis-complex will form. In the case of 1:2, the storage modulus was decreased because catechol makes more mono complexes, owing to excess $\mathrm{Fe}^{3+}$ ions (Figure 5c).

In addition, the cohesive ability was measured based on the change in $\mathrm{pH}$ when the amount of $\mathrm{Fe}^{3+}$ ions was at a constant 2:1 molar ratio. Hydrogel formation was observed throughout the entire $\mathrm{pH}$ range $(\mathrm{pH} 5-10)$, with the largest storage modulus (185 $\mathrm{Pa})$ observed at $\mathrm{pH} 10$. This is because the tri-complex that is formed exhibits a much denser crosslinking (Figure 5d) [39].

To verify the shear thinning property, the shear viscosity based on the shear rate was evaluated. From a shear rate between $0 \mathrm{~s}^{-1}$ and $0.6 \mathrm{~s}^{-1}$, shear thickening properties are observed throughout the $\mathrm{pH}$ range ( $\mathrm{pH} 5$ to 10). However, over $0.6 \mathrm{~s}^{-1}$, shear-thinning properties were observed at all $\mathrm{pH}$ ranges (Figure $5 \mathrm{e}$ ).

\subsection{Adhesion Properties of $\mathrm{Fe}^{3+}$ Induced $\mathrm{HA}-\mathrm{Ca}$ Hydrogels}

$\mathrm{Fe}^{3+}$ ions improve the cohesion strength by coordinating with the hydroxyl groups of catechol. Because hydrogen bonding is the strongest interaction among molecularmolecular interactions, it was expected that the adhesion strength would drop rapidly as the hydroxyl group forms coordination bonds with $\mathrm{Fe}^{3+}$ ions. Therefore, it was hypothesized that the adhesive property of the hydrogel would be lowered based on the degree of crosslinking with $\mathrm{Fe}^{3+}$ ions. Previous data showed that the degree of crosslinking can vary based on the $\mathrm{pH}$ and the amount of $\mathrm{Fe}^{3+}$ ions. To determine the cohesive property variation based on each variable, a rheological test was performed in the two groups. The first group was used to investigate the effect of $\mathrm{pH}$ while fixing the molar ratio of $\mathrm{Fe}^{3+}$ to 2:1 (=Ca: $\left.\mathrm{Fe}^{3+}\right)$. The second group was used to investigate the effect of $\mathrm{Fe}^{3+}$ ions while maintaining the $\mathrm{pH}$ at 7 . As expected, it was observed that the adhesion strength of the more crosslinked hydrogel (1:1 catechol: $\mathrm{Fe}^{3+}$ molar ratio) was lower than that of the less crosslinked hydrogel (2:1 molar ratio) (Figure 5f). Similar results were obtained when the $\mathrm{pH}$ was changed while keeping the molar ratio of $\mathrm{FeCl}_{3}$ constant. When $\mathrm{pH} 5$ and $\mathrm{pH} 10$ were compared, the storage modulus was larger at $\mathrm{pH} 10$; however, the adhesion strength was smaller (1.0 kPa at pH 5 and $0.5 \mathrm{kPa}$ at $\mathrm{pH} 10$ ) (Figure $5 \mathrm{~g}$ ) and can be visibly seen in Figure 5h. The reason is that when the same amount of catechol and $\mathrm{Fe}^{3+}$ ions exist, the tri-complex formed can grab more catechol by forming a tri-complex. These results indicate that adhesion decreases with the degree of cohesion.

In summary, we reported the correlation between cohesion and adhesion strength based on the crosslinking pathways and crosslinking density. When the crosslinking mechanisms are compared, non-covalently bonded hydrogels obtained via metal-catechol coordination showed similar storage modulus; however, adhesion strength was lower than that of the covalently bonded hydrogel.

Depending on the type of oxidant, the HA-Ty hydrogel crosslinked with HRP used by biological oxidants showed the highest as well as the lowest cohesion strength. In the case of $\mathrm{HA}-\mathrm{Ca}$, the radical scavenging ability was stronger than that of $\mathrm{HA}-\mathrm{Ca}$, allowing it to form less crosslinking with the biological oxidant, HRP. However, the adhesion was higher than that of the HA-Ty hydrogel. In comparison with $\mathrm{HA}-\mathrm{Ca}$, the $\mathrm{NaIO}_{4}$ hydrogel showed high adhesion strength and low cohesion strength. In contrast, the $\mathrm{Fe}^{3+}$ ion hydrogel had a fine cohesion strength; however, the adhesion strength was weak. Among the hydrogels tested, the APS hydrogel exhibited the best adhesion strength and showed a good storage modulus, similar to that of the $\mathrm{Fe}^{3+}$ hydrogel. In situations where both good cohesion and good adhesion are required, the APS-induced hydrogel is an option (Figure 6). 


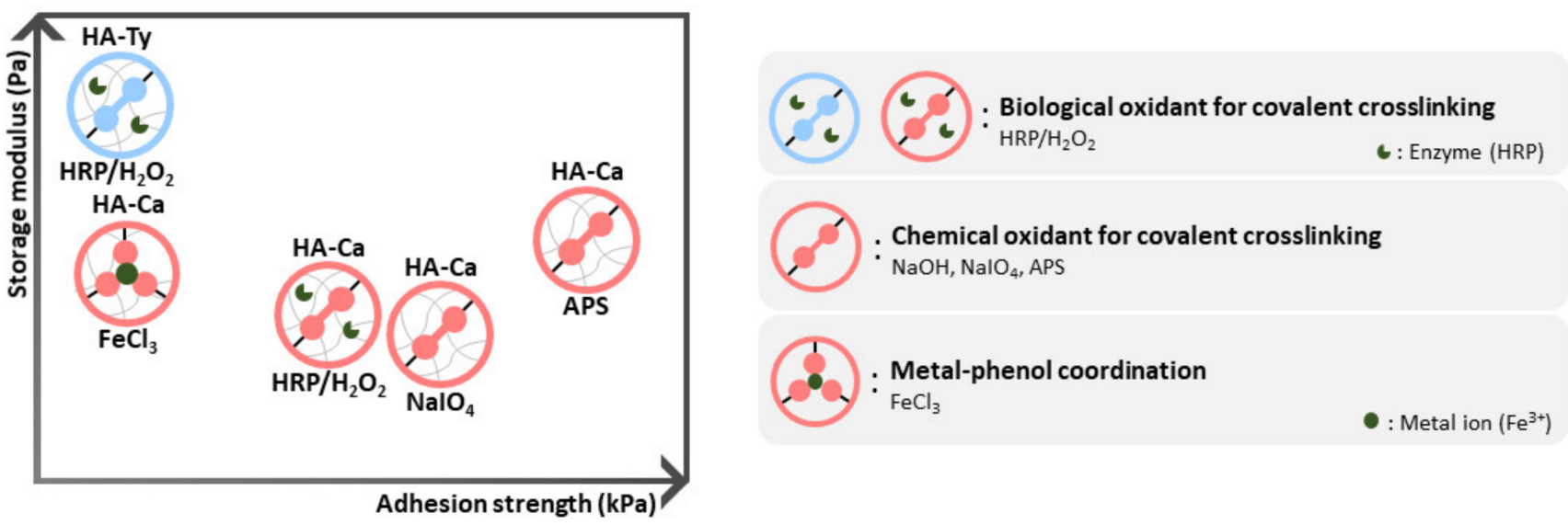

Figure 6. Correlation of adhesion and cohesion strength varying by crosslinking mechanisms. Hydrogels are indicated in the graph (left) based on the level of adhesion strength and storage modulus.

\section{Conclusions}

In conclusion, the correlation between cohesive and adhesive strength of phenolHA hydrogels depending on their crosslinking pathway was investigated. Regarding mechanical properties of the hydrogels crosslinked by enzymatic reaction, HA-Ty formed a stiff hydrogel with high storage modulus of $\sim 10^{3} \mathrm{~Pa}$ when compared to that HA-Ca. However, their adhesiveness was 21 times lower than that of HA-Ca. When the HA-Ca was covalently crosslinked by APS, the storage modulus increased up to $\sim 10^{2} \mathrm{~Pa}$, which was still lower than that of HA-Ty. That is, HA-Ty hydrogels showed strong cohesion yet weak adhesion. Among different oxidation methods (e.g., covalent or non-covalent bonds) to crosslink HA-Ca, the best option to achieve strong adhesion and cohesion was APS-triggered crosslinking. Although metal coordination network with catechol improved cohesion, their adhesive strength did not increase because most of catechols to show adhesiveness were strongly bound to metal ions. The di-catechol covalent bonds can enhance adhesion of the hydrogels due to prevention of cohesive failure. Our finding would be useful for choosing design rationale of the phenol-conjugated polymers with both robust adhesion and cohesion.

Supplementary Materials: The following are available online at https: / / www.mdpi.com/article/ 10.3390 / polym13183130/s1, Supplementary Figure S1: Synthesis and characterization of hyaluronic acid (HA)-based conjugates. Supplementary Figure S2: UV-vis spectra of free dopamine $\left(\mathrm{A}_{280}\right)$ released from the HRP-induced HA-Ca hydrogels. Supplementary Figure S3: UV-vis spectra of HRPinduced HA-Ca hydrogel. Supplementary Figure S4: SEM images (1st photos) and EDS mapping (2nd image for carbon $(\mathrm{C})$, 3rd image for nitrogen $(\mathrm{N})$, and 4th image for oxygen $(\mathrm{O})$ ). Supplementary Figure S5: Rheological characterization of HRP-induced HA-Ca hydrogels in different molar ratios of Ca: $\mathrm{H}_{2} \mathrm{O}_{2}$. Supplementary Figure S6: Swelling ratio (\%) of $\mathrm{HRP} / \mathrm{H}_{2} \mathrm{O}_{2}$-induced $\mathrm{HA}-\mathrm{Ca}$ (red) and HA-Ty (blue) hydrogels as a function of time. Supplementary Figure S7: Rheological characterization of APS-induced HA-Ty hydrogels in different molar ratios of Ty: $\mathrm{H}_{2} \mathrm{O}_{2}$. Supplementary Figure S8: Degradation of HA-Ca hydrogels after swelling of $24 \mathrm{~h}$.

Author Contributions: Conceptualization, M.S.; methodology, M.S., J.K. and S.K.; software, J.K.; validation, J.K.; formal analysis, M.S. and J.K.; investigation, J.K.; resources, M.S. and J.K.; data curation, M.S.; writing—original draft preparation, J.K.; writing—review and editing, M.S.; visualization, J.K.; supervision, M.S. and D.S.; project administration, M.S. and D.S.; funding acquisition, M.S. All authors have read and agreed to the published version of the manuscript.

Funding: This study was supported by the National Research Foundation of Korea (NRF) through a grant funded by the Korean government (MSIT) (NRF-2020R1C1C1003903 to M.S. and NRF2020R1C1C1005567 to D.S.).

Institutional Review Board Statement: Not applicable. 
Informed Consent Statement: Not applicable.

Data Availability Statement: The data presented in this study are available in the article.

Conflicts of Interest: The funders had no role in the study design; collection, analyses, or data interpretation; in the writing of the manuscript; or in the decision to publish the results.

\section{References}

1. Smith, A.M.; Moxon, S.; Morris, G. Biopolymers as wound healing materials. In Wound Healing Biomaterials, 1st ed.; Ågren, M., Ed.; Woodhead Publishing: Sawston, UK, 2016; Volume 2, pp. 261-287.

2. Song, W.; Lee, B.H.; Tan, L.P.; Li, H. Cardiovascular engineering materials in translational medicine. In Biomaterials in Translational Medicine, 1st ed.; Yang, L., Bhaduri, S., Webster, T., Eds.; Woodhead Publishing: Sawston, UK, 2018; Volume 1, pp. 57-91.

3. Iio, K.; Furukawa, K.-I.; Tsuda, E.; Yamamoto, Y.; Maeda, S.; Naraoka, T.; Kimura, Y.; Ishibashi, Y. Hyaluronic acid induces the release of growth factors from platelet-rich plasma. Asia-Pac. J. Sports Med. Arthrosc. Rehabil. Technol. 2019, 4, 27-32. [CrossRef]

4. Voinchet, V.; Vasseur, P.; Kern, J. Efficacy and safety of hyaluronic acid in the management of acute wounds. Am. J. Clin. Dermatol. 2006, 7, 353-357. [CrossRef] [PubMed]

5. Khunmanee, S.; Jeong, Y.; Park, H. Crosslinking method of hyaluronic-based hydrogel for biomedical applications. J. Tissue Eng. 2017, 8, 2041731417726464. [CrossRef]

6. Fallacara, A.; Baldini, E.; Manfredini, S.; Vertuani, S. Hyaluronic acid in the third millennium. Polymers 2018, 10, 701. [CrossRef]

7. Shin, J.; Choi, S.; Kim, J.H.; Cho, J.H.; Jin, Y.; Kim, S.; Min, S.; Kim, S.K.; Choi, D.; Cho, S.W. Tissue Tapes-Phenolic Hyaluronic Acid Hydrogel Patches for Off-the-Shelf Therapy. Adv. Funct. Mater. 2019, 29, 1903863. [CrossRef]

8. Trombino, S.; Servidio, C.; Curcio, F.; Cassano, R. Strategies for hyaluronic acid-based hydrogel design in drug delivery. Pharmaceutics 2019, 11, 407. [CrossRef] [PubMed]

9. Petta, D.; Grijpma, D.W.; Alini, M.; Eglin, D.; D’Este, M. Three-dimensional printing of a tyramine hyaluronan derivative with double gelation mechanism for independent tuning of shear thinning and postprinting curing. ACS Biomater. Sci. Eng. 2018, 4, 3088-3098. [CrossRef] [PubMed]

10. Le Thi, P.; Son, J.Y.; Lee, Y.; Ryu, S.B.; Park, K.M.; Park, K.D. Enzymatically crosslinkable hyaluronic acid-gelatin hybrid hydrogels as potential bioinks for tissue regeneration. Macromol. Res. 2020, 28, 400-406. [CrossRef]

11. Zhou, L.; Dai, C.; Fan, L.; Jiang, Y.; Liu, C.; Zhou, Z.; Guan, P.; Tian, Y.; Xing, J.; Li, X.; et al. Injectable Self-Healing Natural Biopolymer-Based Hydrogel Adhesive with Thermoresponsive Reversible Adhesion for Minimally Invasive Surgery. Adv. Funct. Mater. 2021, 31, 2007457. [CrossRef]

12. Stern, R.; Asari, A.A.; Sugahara, K.N. Hyaluronan fragments: An information-rich system. Eur. J. Cell Biol. 2006, 85, 699-715. [CrossRef] [PubMed]

13. Buhren, B.A.; Schrumpf, H.; Hoff, N.-P.; Bölke, E.; Hilton, S.; Gerber, P.A. Hyaluronidase: From clinical applications to molecular and cellular mechanisms. Eur. J. Med. Res. 2016, 21, 1-7. [CrossRef] [PubMed]

14. Burdick, J.A.; Prestwich, G.D. Hyaluronic acid hydrogels for biomedical applications. J. Adv. Mater. 2011, 23, H41-H56. [CrossRef] [PubMed]

15. Paap, M.K.; Silkiss, R.Z. The interaction between hyaluronidase and hyaluronic acid gel fillers-a review of the literature and comparative analysis. Plast. Aesthet. Res. 2020, 7, 220514027. [CrossRef]

16. Wang, G.; Cao, X.; Dong, H.; Zeng, L.; Yu, C.; Chen, X. A hyaluronic acid based injectable hydrogel formed via photo-crosslinking reaction and thermal-induced diels-alder reaction for cartilage tissue engineering. Polymers 2018, 10, 949. [CrossRef]

17. Yoon, H.Y.; Koo, H.; Choi, K.Y.; Kwon, I.C.; Choi, K.; Park, J.H.; Kim, K. Photo-crosslinked hyaluronic acid nanoparticles with improved stability for in vivo tumor-targeted drug delivery. Biomaterials 2013, 34, 5273-5280. [CrossRef] [PubMed]

18. Hu, X.; Gao, Z.; Tan, H.; Wang, H.; Mao, X.; Pang, J. An injectable hyaluronic acid-based composite hydrogel by DA click chemistry with $\mathrm{pH}$ sensitive nanoparticle for biomedical application. Front. Chem. 2019, 7, 477. [CrossRef] [PubMed]

19. Zaokari, Y.; Persaud, A.; Ibrahim, A. Biomaterials for adhesion in orthopedic applications: A review. Eng. Regen. 2020, 1, 51-63. [CrossRef]

20. Lee, J.S.; Cho, J.H.; An, S.; Shin, J.; Choi, S.; Jeon, E.J.; Cho, S.-W. In situ self-cross-linkable, long-term stable hyaluronic acid filler by gallol autoxidation for tissue augmentation and wrinkle correction. Chem. Mater. 2019, 31, 9614-9624. [CrossRef]

21. Dai, Q.; Geng, H.; Yu, Q.; Hao, J.; Cui, J. Polyphenol-based particles for theranostics. Theranostics 2019, 9, 3170. [CrossRef]

22. Yang, J.; Stuart, M.A.C.; Kamperman, M. Jack of all trades: Versatile catechol crosslinking mechanisms. Chem. Soc. Rev. 2014, 43, 8271-8298. [CrossRef]

23. Loebel, C.; Szczesny, S.E.; Cosgrove, B.D.; Alini, M.; Zenobi-Wong, M.; Mauck, R.L.; Eglin, D. Cross-linking chemistry of tyramine-modified hyaluronan hydrogels alters mesenchymal stem cell early attachment and behavior. Biomacromolecules 2017, 18, 855-864. [CrossRef]

24. Gan, D.; Xu, T.; Xing, W.; Wang, M.; Fang, J.; Wang, K.; Ge, X.; Chan, C.W.; Ren, F.; Tan, H.; et al. Mussel-inspired dopamine oligomer intercalated tough and resilient gelatin methacryloyl (GelMA) hydrogels for cartilage regeneration. J. Mater. Chem. B 2019, 7, 1716-1725. [CrossRef] [PubMed] 
25. Abu-Hakmeh, A.; Kung, A.; Mintz, B.R.; Kamal, S.; Cooper, J.A.; Lu, X.L.; Wan, L.Q. Sequential gelation of tyramine-substituted hyaluronic acid hydrogels enhances mechanical integrity and cell viability. Med. Biol. Eng. Comput. 2016, 54, 1893-1902. [CrossRef] [PubMed]

26. Thi, T.T.H.; Lee, Y.; Le Thi, P.; Park, K.D. Engineered horseradish peroxidase-catalyzed hydrogels with high tissue adhesiveness for biomedical applications. J. Ind. Eng. Chem. 2019, 78, 34-52.

27. Park, M.K.; Li, M.-X.; Yeo, I.; Jung, J.; Yoon, B.-I.; Joung, Y.K. Balanced adhesion and cohesion of chitosan matrices by conjugation and oxidation of catechol for high-performance surgical adhesives. Carbohydr. Polym. 2020, 248, 116760. [CrossRef] [PubMed]

28. Larrañeta, E.; Henry, M.; Irwin, N.J.; Trotter, J.; Perminova, A.A.; Donnelly, R.F. Synthesis and characterization of hyaluronic acid hydrogels crosslinked using a solvent-free process for potential biomedical applications. Carbohydr. Polym. 2018, 181, 1194-1205. [CrossRef]

29. Hong, S.; Yang, K.; Kang, B.; Lee, C.; Song, I.T.; Byun, E.; Park, K.I.; Cho, S.W.; Lee, H. Hyaluronic acid catechol: A biopolymer exhibiting a $\mathrm{pH}$-dependent adhesive or cohesive property for human neural stem cell engineering. Adv. Funct. Mater. 2013, 23, 1774-1780. [CrossRef]

30. Ryu, J.H.; Hong, S.; Lee, H. Bio-inspired adhesive catechol-conjugated chitosan for biomedical applications: A mini review. Acta Biomater. 2015, 27, 101-115. [CrossRef]

31. Lee, F.; Chung, J.E.; Kurisawa, M. An injectable enzymatically crosslinked hyaluronic acid-tyramine hydrogel system with independent tuning of mechanical strength and gelation rate. Soft Matter 2008, 4, 880-887. [CrossRef]

32. Guo, Z.; Mi, S.; Sun, W. The multifaceted nature of catechol chemistry: Bioinspired pH-initiated hyaluronic acid hydrogels with tunable cohesive and adhesive properties. J. Mater. Chem. B. 2018, 6, 6234-6244. [CrossRef]

33. Lee, B.P.; Dalsin, J.L.; Messersmith, P.B. Synthesis and gelation of DOPA-modified poly (ethylene glycol) hydrogels. Biomacromolecules 2002, 3, 1038-1047. [CrossRef] [PubMed]

34. Ferretti, A.; Prampolini, G.; d'Ischia, M. Noncovalent interactions in catechol/ammonium-rich adhesive motifs: Reassessing the role of cation- $\pi$ complexes? Chem. Phys. Lett. 2021, 779, 138815. [CrossRef]

35. Hong, B.M.; Park, S.A.; Park, W.H. Effect of photoinitiator on chain degradation of hyaluronic acid. Biomater. Res. 2019, 23, 1-8. [CrossRef] [PubMed]

36. De Souza, A.B.; Chaud, M.V.; Santana, M.H.A. Hyaluronic acid behavior in oral administration and perspectives for nanotechnology-based formulations: A review. Carbohydr. Polym. 2019, 222, 115001. [CrossRef]

37. Bijlsma, J.; de Bruijn, W.J.; Hageman, J.A.; Goos, P.; Velikov, K.P.; Vincken, J.-P. Revealing the main factors and two-way interactions contributing to food discolouration caused by iron-catechol complexation. Sci. Rep. 2020, 10, 1-11.

38. Lee, J.; Chang, K.; Kim, S.; Gite, V.; Chung, H.; Sohn, D. Phase controllable hyaluronic acid hydrogel with iron (III) ion-Catechol induced dual cross-linking by utilizing the gap of gelation kinetics. Macromolecules 2016, 49, 7450-7459. [CrossRef]

39. Holten-Andersen, N.; Harrington, M.J.; Birkedal, H.; Lee, B.P.; Messersmith, P.B.; Lee, K.Y.C.; Waite, J.H. pH-induced metal-ligand cross-links inspired by mussel yield self-healing polymer networks with near-covalent elastic moduli. Proc. Natl. Acad. Sci. USA 2011, 108, 2651-2655. [CrossRef] 